\title{
Systematic Review of the Addition of Hip Strengthening Exercises for Adults with Patellofemoral Pain Syndrome
}

\author{
Cara Elliott \\ Fraser Green \\ Karen Hang \\ Bronwen Jolliffe \\ Maureen P. McEvoy \\ University of South Australia, maureen.mcevoy@unisa.edu.au
}

Follow this and additional works at: https://nsuworks.nova.edu/ijahsp

Part of the Physiotherapy Commons

\section{Recommended Citation}

Cara Elliott , Fraser Green , Karen Hang , Bronwen Jolliffe , McEvoy MP. Systematic Review of the Addition of Hip Strengthening Exercises for Adults with Patellofemoral Pain Syndrome. The Internet Journal of Allied Health Sciences and Practice. 2018 Jan 01;16(4), Article 10.

This Manuscript is brought to you for free and open access by the College of Health Care Sciences at NSUWorks. It has been accepted for inclusion in Internet Journal of Allied Health Sciences and Practice by an authorized editor of NSUWorks. For more information, please contact nsuworks@nova.edu. 


\title{
Systematic Review of the Addition of Hip Strengthening Exercises for Adults with Patellofemoral Pain Syndrome
}

\begin{abstract}
Patellofemoral Pain Syndrome (PFPS) is a common musculoskeletal disorder typically occurring in physically active people aged 40 years and younger, causing pain, functional deficits and lower limb weakness. Traditional treatment has been aimed at strengthening the knee, however recent research suggests the muscles around the hip also play an important role in the development and continuity of Patellofemoral Pain Syndrome.

Purpose: To investigate the effectiveness of the addition of hip strengthening exercises to standard physiotherapy treatment (knee strengthening and stretching exercises) on reducing pain, and enhancing strength and function when compared to standard physiotherapy treatment alone in adults with Patellofemoral Pain Syndrome.

Method: A systematic search of Cochrane, CINAHL, Embase, MEDLINE®, PEDro and SportDiscus was conducted. Studies of participants aged 18 to 44, diagnosed with Patellofemoral Pain Syndrome by a healthcare practitioner, or reporting peripatellar or retropatellar pain with common functional tasks, were included. A critical appraisal, using the Critical Appraisal Skills Program for Randomised Controlled Trials (CASP) was used to assess methodological quality.

Results: Five randomised controlled trials of varying methodological quality met the inclusion criteria. The participants in these studies were aged between 18 to 40 years of age. The duration of the intervention ranged from four to six weeks consisting of 12 to 30 supervised exercise sessions. Studies used varying outcome measures for each of the three outcomes. Overall, the studies demonstrated that the addition of hip strengthening exercises to standard physiotherapy care consistently improved pain and function, but the impact on strength was variable.

Conclusion: Previously, only a small number of studies have looked at the addition of hip exercises to standard physiotherapy care for treatment of Patellofemoral Pain Syndrome. While there is a growing body of evidence for the efficacy of hip strengthening exercises for Patellofemoral Pain Syndrome, this is constrained by bias towards female participants, lack of true controls in most studies, and low methodological quality of studies overall. Hip exercises added to standard physiotherapy care shows potential as a treatment method for improving outcomes of pain and function in adults with Patellofemoral Pain Syndrome.
\end{abstract}

\section{Author Bio(s)}

Cara Elliott, is a graduate physiotherapist from the University of South Australia.

Fraser Green, is a graduate physiotherapist from the University of South Australia.

Karen Hang is a graduate physiotherapist from University of South Australia.

Bronwen Jolliffe, graduate physiotherapist who has a passion for musculoskeletal and neurological rehabilitation.

Maureen McEvoy PhD, lecturer in the School of Health Sciences with clinical and research involvements in Evidence-Based Practice and musculoskeletal physiotherapy. 


\title{
TIAHSP \\ The Internet Joưnal of Allied Health Sciences and Practice
}

Dedicated to allied health professional practice and education

Vol. 16 No. 4 ISSN 1540-580X

\section{Systematic Review of the Addition of Hip Strengthening Exercises for Adults with Patellofemoral Pain Syndrome}

\author{
Cara Elliott, BPhty \\ Fraser Green, BPhty \\ Karen Hang, BPhty \\ Bronwen Jolliffe, BPhty \\ Maureen P. McEvoy, PhD \\ University of South Australia
}

Australia

\begin{abstract}
Patellofemoral Pain Syndrome (PFPS) is a common musculoskeletal disorder typically occurring in physically active people aged 40 years and younger, causing pain, functional deficits, and lower limb weakness. Traditional treatment has been aimed at strengthening the knee, however, recent research suggests the muscles around the hip play an important role in the development and continuity of Patellofemoral Pain Syndrome. Purpose: To investigate the effectiveness of the addition of hip strengthening exercises to standard physiotherapy treatment (knee strengthening and stretching exercises) on reducing pain and enhancing strength and function when compared to standard physiotherapy treatment alone in adults with Patellofemoral Pain Syndrome. Method: A systematic search of Cochrane, CINAHL, Embase, MEDLINE®, PEDro, and SportDiscus was conducted. Studies of participants aged 18 to 44, diagnosed with PFPS by a healthcare practitioner, or reporting peripatellar or retropatellar pain with common functional tasks, were included. A critical appraisal, using the Critical Appraisal Skills Program for Randomised Controlled Trials (CASP) was used to assess methodological quality. Results: Five randomised controlled trials of varying methodological quality met the inclusion criteria. The participants in these studies were aged between 18 and 40 years of age. The duration of the intervention ranged from four to six weeks consisting of 12 to 30 supervised exercise sessions. Studies used varying outcome measures for each of the three outcomes. Overall, the studies demonstrated that the addition of hip strengthening exercises to standard physiotherapy care consistently improved pain and function, but the impact on strength was variable. Conclusion: Only a small number of studies have looked at the addition of hip exercises to standard physiotherapy care for the treatment of Patellofemoral Pain Syndrome. While there is a growing body of evidence for the efficacy of hip strengthening exercises for Patellofemoral Pain Syndrome, the studies tend to be constrained by bias towards female participants, lack of true controls, and low methodological quality of studies overall. Hip exercises added to standard physiotherapy care shows potential as a treatment approach for improving outcomes of pain and function in adults with Patellofemoral Pain Syndrome.
\end{abstract}

\section{BACKGROUND}

Patellofemoral Pain Syndrome (PFPS) is a common musculoskeletal disorder typically occurring in physically active people aged 40 years and younger. ${ }^{1}$ Prevalence ranges for PFPS are reported to be from $15 \%$ to $33 \%$ in adults, and $21 \%$ to $45 \%$ in active adolescents. ${ }^{2}$ This syndrome is considered the most common overuse injury of the lower limb in active individuals, accounting for $11 \%$ to $17 \%$ of all knee pain presentations in general practice.1,3 Common symptoms include diffuse peripatellar or localised retropatellar pain during activities such as running, moving up or down stairs, squatting, and sitting with knees bent for prolonged periods. ${ }^{4}$ The clinical presentation of PFPS often includes muscular weakness and altered lower limb biomechanics. ${ }^{5}$

Traditional treatment methods aim to improve patellar alignment and strengthen muscles surrounding and acting on the knee joint. ${ }^{6}$ However, a recent study by Santos et al. and best practice guidelines developed by Barton et al. suggest that hip biomechanics may play a major role in the development and continuity of PFPS. ${ }^{5,7}$ Hip muscle strengthening to counteract excessive hip flexion, 
adduction, and internal rotation, which exert stress on the patellofemoral joint, has been proposed as additional treatment for PFPS.., 8

A systematic review by Santos et al. explored the effectiveness of hip muscle strengthening in patients with PFPS. ${ }^{5}$ The results suggested that hip strengthening exercises were effective at improving pain and function, however, in addition to a limited number of databases and search terms being used, two included studies used comparator groups that made it difficult to clearly identify the specific effects of the hip strengthening exercises. 5,9,10 A third study by Nakagawa et al. added transversus abdominus exercises to the hip strengthening exercises, also potentially obscuring the true effects of hip strengthening. ${ }^{11}$

The functional problems associated with PFPS in young adults are increasing, particularly with the rise in physical activity to counteract sedentary lifestyles and to promote health and wellbeing. ${ }^{12}$ Hence, this current systematic review is important in order to update the findings of Santos et al. through a more comprehensive search, rigorous selection and appraisal processes, and summary of updated high-quality literature. ${ }^{5}$ This can then be integrated with previous knowledge on the effect of hip strengthening exercises on PFPS to further assist clinicians with important clinical decision making. The systematic review research question was: 'In adults with Patellofemoral Pain Syndrome, what is the effectiveness of the addition of hip strengthening exercises to standard physiotherapy treatment on pain, strength, and function, when compared with standard physiotherapy care alone?'

\section{METHODS}

\section{Search Strategy}

This review was conducted and reported in line with the Preferred Reporting Items for Systematic Reviews and Meta Analyses (PRISMA) Statement. ${ }^{13}$ In September 2017, a search was conducted in six electronic databases: Cochrane, Cumulative Index to Nursing and Allied Health Literature (CINAHL), Embase, MEDLINE®, Physiotherapy Evidence Database (PEDro), and SportDiscus. Each database was searched from inception to the date of the search (September 2017). Only studies published in English were included. Table 1 outlines the Participant, Intervention, Comparator, Outcomes (PICO) components of the search question and keywords used in the search strategy. Details of the search strategy are included in Appendix 1.

\begin{tabular}{|l|l|}
\multicolumn{2}{c|}{ Table 1: PICO Search Strategy } \\
\hline Population & \multicolumn{1}{c|}{ Definition } \\
\hline Intervention & Adults (ages 18-44) with Patellofemoral Pain Syndrome (PFPS) \\
\hline Comparator & Hip strengthening exercises in addition to standard physiotherapy care \\
\hline Outcome & Standard physiotherapy care \\
\hline
\end{tabular}

\section{Eligibility Criteria}

Studies were only considered for inclusion based on design if they were controlled trials, including randomised, pseudorandomised, and non-randomised controlled clinical trials. In addition, the reference lists of all systematic reviews and the final studies were searched for further relevant trials. Other primary research evidence including case studies/series, observational studies, cohort studies, case-control studies, and all qualitative research evidence was not considered for inclusion.

\section{Population}

The population of included studies was limited to adults aged 18 to 44 years who had been diagnosed with PFPS by a healthcare practitioner or complained of: 1) the presence of anterior retropatellar knee pain during at least two of the following activities: ascending/descending stairs, squatting, hopping/running, kneeling, and prolonged sitting, 2) insidious onset of symptoms unrelated to a trauma, 3) pain on compression or palpation of the patellar and facets. ${ }^{4,5}$ Study exclusion occurred in the presence of a current significant injury affecting the lower extremity, a history of other knee pathology, any ankle, hip, or lower back/sacroiliac pain, or the use of corticosteroids and/or anti-inflammatory medication.

\section{Intervention}

Studies were considered for inclusion if hip strengthening exercises targeting at least two of the following muscle groups were utilised as an adjunct to standard PFPS physiotherapy treatment directed at the knee: hip external rotators, hip abductors, hip extensors. Studies with comparator groups that focused solely on hip stretching exercises or which included abdominal and other trunk muscle strengthening exercises were excluded. 


\section{Outcome Measures}

Outcomes of interest were at least one or more of the following: pain, function, and strength. Only studies incorporating validated outcome measures were accepted (e.g. visual analogue scale [VAS] for pain, Lower Extremity Functional Scale [LEFS] for function, hand-held dynamometer for strength).

\section{Study Selection}

Two reviewers (FG, BJ) independently undertook the search of each database to ensure consistency and reproducibility. The reviewers compared the number of 'hits' after each database search; where discrepancies occurred, the error was identified and the search re-run until there were no errors. The results from each database were exported into the industry standard bibliographic software tool Endnote ${ }^{\mathrm{TM}}$ to separate database folders. All folders were then combined and duplicates removed. The remaining studies were imported to Covidence, a data management software for systematic reviews, where two rounds of screening took place. In the first round, both reviewers (FG, BJ) independently screened all study titles and abstracts. Any disagreement that arose was resolved using the following system: Maybe + Yes $=$ Yes, Maybe + Maybe $=$ Yes, Maybe + No $=$ No, Yes $+\mathrm{No}=$ conflict. Both reviewers met to discuss and resolve any conflicts. Full text was obtained for all studies where there was insufficient detail in the abstract to determine eligibility, where there was no available abstract, or where the study was likely to be included based on title and abstract. A second round of screening of the full text of each study against the eligibility criteria was then undertaken by the same two reviewers (FG, BJ) and reasons for exclusions were recorded. Discrepancies about eligibility that could not be resolved by the two reviewers were resolved via a face-to-face discussion with the remaining two reviewers (KH, CE).

\section{Risk of Bias}

The methodological quality of each included study was assessed independently by all four reviewers using the Critical Appraisal Skills Program (CASP) Randomised Controlled Trial critical appraisal tool..$^{14}$ Initially, reviewers met to discuss the agreed interpretation of items in the CASP, where a scoring system of, yes $=1$, no and can't tell $=0$, was used. Reviewers then met to compare findings of each CASP and any disagreements were discussed until consensus was reached. Potential methodological and reporting biases not formally assessed by the CASP were also independently considered by two team reviewers and then discussed to resolve any conflicts.

The hierarchy of all studies was assessed according to the National Health and Medical Research Council (NHMRC) designation of levels of evidence. ${ }^{15} \mathrm{An}$ agreed interpretation of results was previously established by all research team members and disagreements were resolved through discussion with the project supervisor (MM).

\section{Data Extraction}

The data were extracted by two reviewers $(\mathrm{KH}, \mathrm{CE})$ and collated into a specifically customised template which included information relating to the population, intervention, comparator, outcome measures, and results. The process of data extraction using this template was previously tested with one study by both reviewers together to ensure data would be interpreted and extracted consistently. Data extraction of the remaining studies was then completed independently, and findings were compared between the same two reviewers before the process of condensing and refining was implemented. Any disagreements that arose through the extraction process were resolved through face-to-face discussion with all reviewers. A narrative analysis of included studies was subsequently performed as the small number of studies and variability in outcome measures meant a meta-analysis was not appropriate. The statistical effects of the interventions on validated measures for pain, function, and strength were presented and compared using p-values with an alpha level set at 0.05 or using $95 \%$ confidence intervals.

\section{Data Synthesis}

A review team utilised the NHMRC FORM methodology to grade and provide a framework to synthesise the evidence from the literature. ${ }^{15}$ The NHMRC FORM methodology considers the evidence provided in all studies to assist in the development of a specific recommendation. There are five main components: 1) quantity and quality of the evidence, 2) consistency, 3) clinical impact, 4) generalisability, and 5) applicability. This framework provided a basis for evidence-based recommendations for implementation in clinical practice and identified where care may need to be taken in the application of the findings. ${ }^{15}$

\section{RESULTS \\ Search Results}

The search strategy generated 200 'hits' with an additional one record being identified through other sources. Following removal of duplicates, title and abstract screening, and screening of full-text versions, five studies were included in the review. The authors also followed-up a Persian study by Soleimani et al. with an English abstract, but no full text version in English was available. ${ }^{16}$ There was no response to a request from the authors, so the study was excluded. Figure 1 provides an overview of the literature selection process.

(C) The Internet Journal of Allied Health Sciences and Practice, 2018 


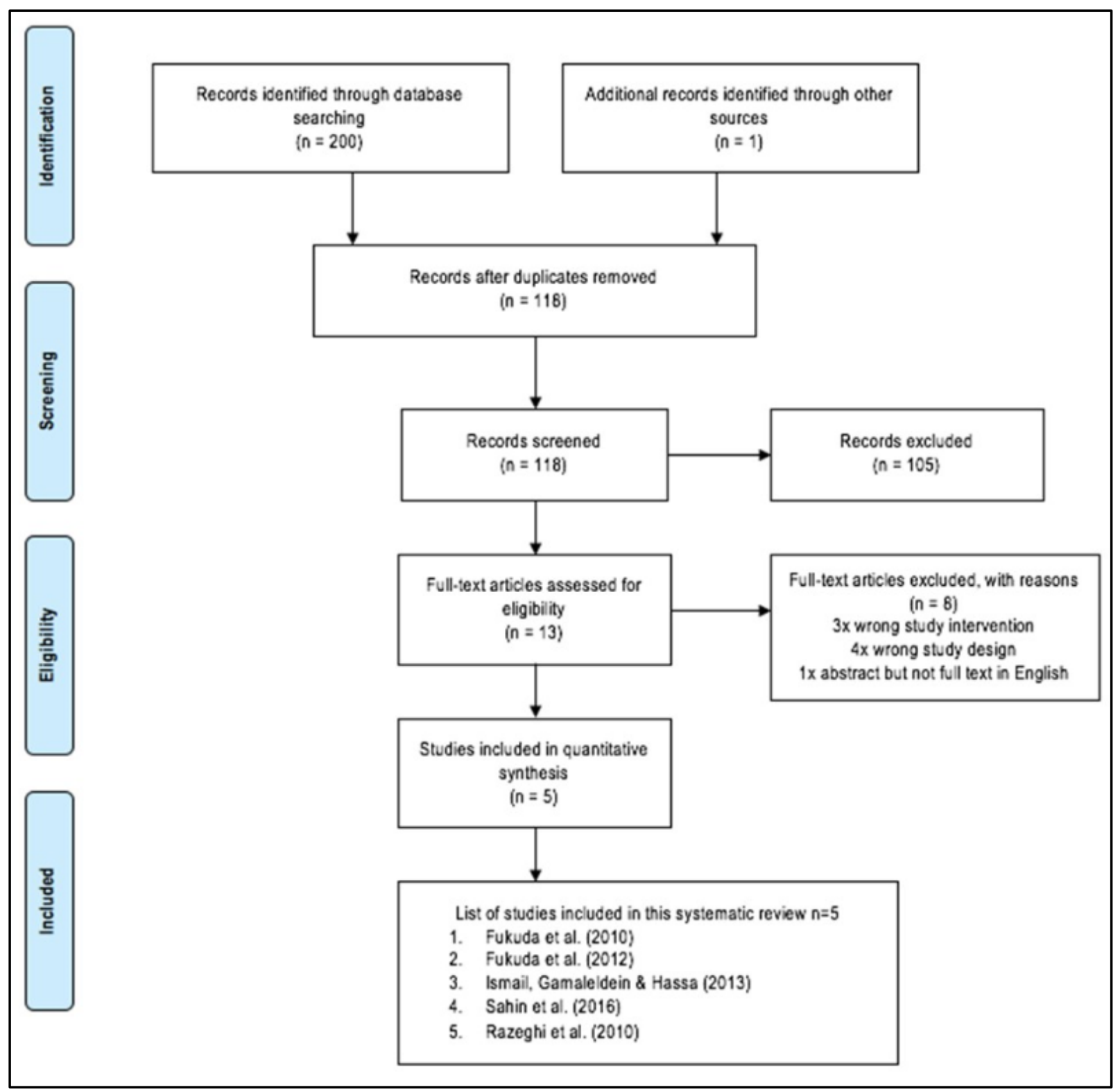

Figure 1

\section{Ranking and Methodological Quality}

An overview of the NHMRC designation of levels of evidence and a summary of the collated findings and consensus agreement from the four researchers for the critical appraisal for individual studies is presented in Table $2 .{ }^{14} \mathrm{All}$ studies scored between five to nine out of a possible total score of 10 (Table 2 ). ${ }^{13}$ 
Table 2: CASP Scores of each included study

\begin{tabular}{|c|c|c|c|c|c|}
\hline \multirow{3}{*}{$\begin{array}{l}\text { Critical Appraisal Skills Program } \\
\text { for Randomised Controlled Trials } \\
\text { (CASP) Question Number }\end{array}$} & \multicolumn{5}{|c|}{ Study } \\
\hline & Fukuda et al. ${ }^{17}$ & $\begin{array}{c}\text { Fukuda et } \\
\text { al. }{ }^{18}\end{array}$ & Ismail et al. ${ }^{19}$ & Sahin et al..$^{20}$ & $\begin{array}{c}\text { Razeghi et } \\
\text { al. }{ }^{21}\end{array}$ \\
\hline & $\begin{array}{l}\text { RCT (NHMRC } \\
\text { III-1) }\end{array}$ & $\begin{array}{l}\text { RCT (NHMRC } \\
\text { III-1) }\end{array}$ & $\begin{array}{c}\text { RCT (NHMRC } \\
\text { III-1) }\end{array}$ & $\begin{array}{c}\text { RCT (NHMRC } \\
\text { III-1) }\end{array}$ & $\begin{array}{c}\text { RCT } \\
\text { (NHMRC III-1) }\end{array}$ \\
\hline $\begin{array}{l}\text { Q1: Did the trial address a clearly } \\
\text { focused issue? }\end{array}$ & 1 & 1 & 1 & 1 & 1 \\
\hline $\begin{array}{l}\text { Q2: Was the assignment of patients } \\
\text { to treatment groups randomised? }\end{array}$ & 1 & 1 & 1 & 1 & 0 \\
\hline $\begin{array}{l}\text { Q3: Were all of the patients who } \\
\text { entered the trial properly accounted } \\
\text { for at its conclusion? }\end{array}$ & 1 & 1 & 1 & 0 & 0 \\
\hline $\begin{array}{l}\text { Q4: Were patients, health workers } \\
\text { and study personnel 'blind' to } \\
\text { treatment? }\end{array}$ & 0 & 0 & 0 & 0 & 0 \\
\hline $\begin{array}{l}\text { Q5: Were the groups similar at the } \\
\text { start of the trial? }\end{array}$ & 1 & 1 & 1 & 1 & 0 \\
\hline $\begin{array}{l}\text { Q6: Aside from the experimental } \\
\text { intervention, were the groups treated } \\
\text { equally? }\end{array}$ & 1 & 1 & 1 & 1 & 1 \\
\hline $\begin{array}{l}\text { Q7: How large was the treatment } \\
\text { effect?* }^{\text {a }}\end{array}$ & & & & & \\
\hline $\begin{array}{l}\text { Q8: How precise was the estimate } \\
\text { of the treatment effect? }\end{array}$ & $\begin{array}{c}\mathrm{Cl}=95 \% \\
1\end{array}$ & $\begin{array}{c}\mathrm{Cl}=95 \% \\
1\end{array}$ & $\begin{array}{c}\mathrm{Nil} \mathrm{Cl} \\
0\end{array}$ & $\begin{array}{c}\mathrm{Nil} C l \\
0\end{array}$ & $\begin{array}{c}\mathrm{Cl}=95 \% \\
1\end{array}$ \\
\hline $\begin{array}{l}\text { Q9: Can the results be applied in } \\
\text { your context? }\end{array}$ & 1 & 1 & 1 & 1 & 1 \\
\hline $\begin{array}{l}\text { Q10: Were all clinically important } \\
\text { outcomes considered? }\end{array}$ & 1 & 1 & 1 & 1 & 0 \\
\hline $\begin{array}{l}\text { Q11: Are the benefits worth the } \\
\text { harms and costs? }\end{array}$ & 1 & 1 & 1 & 1 & 1 \\
\hline TOTAL SCORE /10 & $9 / 10$ & $9 / 10$ & $8 / 10$ & $7 / 10$ & $5 / 10$ \\
\hline TOTAL SCORE \% & $90 \%$ & $90 \%$ & $80 \%$ & $70 \%$ & $50 \%$ \\
\hline
\end{tabular}

Scoring: Yes $=1, \mathrm{No}=0$, Can't tell $=0$. ${ }^{*}$ Question 7 did not require a score to be allocated.

The CASP analysis revealed several inherent methodological biases across the studies. All studies had focused questions, treated the intervention and comparator groups equally, and presented results that could be applied and would be considered beneficial. Except for the study by Razeghi et al, the randomisation process was undertaken well, and the groups were similar at the commencement of the trial. In no study were participants blinded to the treatment, which is not surprising due to the nature of both interventions and comparators. Studies scored "0" on the third CASP item if they did not employ an intention to treat analysis or did not provide explanations for participant dropout. ${ }^{14}$ Only studies by Sahin et al and Razeghi et al demonstrated the potential for significant attrition bias. ${ }^{20,21}$ Finally, all studies provided some statistical measure of the significance of results. However, the precision of results from Sahin et al was deemed inadequate due to the absence of reporting of $95 \%$ confidence intervals. ${ }^{20}$

Team members acknowledged the potential for other biases not formally assessed by the CASP to affect the validity of results. All studies were potentially subject to the Hawthorne effect since both the intervention and comparator involved supervision by an educated therapist. The potential for attention bias must also be acknowledged since in each study, the intervention group received a longer supervised session than the control group. This was due to the additional exercises involved in the intervention. In addition, no explicit mention of the training provided to therapists was provided in any study, potentially contributing to proficiency bias. It was difficult to determine the impact of contamination bias due to a lack of reported restrictions preventing exposure of control groups to the intervention. The study by Ismail et al. did not demonstrate sufficient efforts to eliminate the presence of cointervention bias. ${ }^{19}$ 


\section{Study Characteristics}

Publication dates of the included studies ranged from 2008 to 2016. They comprised of five pseudo-randomised controlled trials. The studies were conducted in Brazil, Egypt, Turkey, and Iran. ${ }^{17-21}$ The characteristics of each study are outlined in Table 3. Specific exercises within each group are detailed in Appendix 2.

\section{Participant Characteristics}

The number of participants in the studies ranged from 32 to 70 and the mean age across the studies ranged between 23 to 34 years. ${ }^{17-21}$ Three of the five studies evaluated sedentary females; ${ }^{17,18,20}$ one additional study by Razeghi et al. evaluated female university students, but it is unclear as to whether they met the sedentary classification. ${ }^{21}$ Ismail et al. was the only study to include both male and female participants. ${ }^{19}$

Table 3: Study Characteristics

\begin{tabular}{|c|c|c|c|c|c|}
\hline Study & $\begin{array}{l}\text { Population (n) } \\
\text { Gender: F/M } \\
\text { Age: mean } \pm S D \\
\text { Status }\end{array}$ & $\begin{array}{l}\text { Intervention } \\
\text { (I) }\end{array}$ & $\begin{array}{l}\text { Comparator } \\
\text { (C) }\end{array}$ & $\begin{array}{l}\text { Outcome: } \\
\text { Measurem } \\
\text { ents (OM) }\end{array}$ & Findings \\
\hline $\begin{array}{l}\text { Fukuda } \\
\text { et al. }{ }^{17}\end{array}$ & $\begin{array}{l}\mathrm{n}=70 \\
70 \mathrm{~F} \\
25 \pm 7(18-32) \\
\text { Sedentary }\end{array}$ & $\begin{array}{l}n=23 \text { Hip: } \\
\text { OKC AB \& } \\
\text { ER + Knee } \\
\text { Protocol } \\
\text { 3x/wk, 4wks }\end{array}$ & $\begin{array}{l}\text { 1. } n=22 \\
\text { Knee } \\
\text { Protocol: } \\
\text { squats, Kn } \\
\text { E, stretch } \\
\text { 3x/wk, 4wks } \\
\text { 2. } n=25 \\
\text { Control: } \\
\text { ADLs }\end{array}$ & $\begin{array}{l}\text { P: NRPS } \\
\text { up/down } \\
\text { stairs } \\
\text { F: LEFS, } \\
\text { AKPS, } \\
\text { SLHT }\end{array}$ & $\begin{array}{l}\text { I \& C: } \\
P: \downarrow(p<0.05, p>0.05 \text { resp. }) \\
F: \uparrow \text { all OM }(p<0.05) \\
\text { Control: Nil change }(p>0.05) \\
\text { I vs C vs Control: } \\
P \text { down stairs: } \downarrow(I \text { cf } C)(p<0.05) \text { \& Control } \\
\text { (p<0.01); } \downarrow(C \text { cf Control) }(p>0.05) \\
F: \uparrow(I \& C>\text { Control): all OM }(p<0.05) \\
F: \uparrow(I \text { cf } C): \text { all OM }(p>0.05)\end{array}$ \\
\hline $\begin{array}{l}\text { Fukuda } \\
\text { et al. } 18\end{array}$ & $\begin{array}{l}n=54 \\
54 \mathrm{~F} \\
23 \pm 3(20-40) \\
\text { Sedentary }\end{array}$ & $\begin{array}{l}n=28 \text { Hip: } \\
\text { OKC AB, ER } \\
\& \text { CKC HE + } \\
\text { Knee } \\
\text { Protocol } \\
\text { 3x/wk, 4wks }\end{array}$ & $\begin{array}{l}n=26 \text { Knee } \\
\text { Protocol: } \\
\text { squats, Kn } \\
\text { E, calf raise, } \\
\text { PKF, stretch } \\
3 x / \text { wk, 4wks }\end{array}$ & $\begin{array}{l}\text { P: NRPS } \\
\text { up/down } \\
\text { stairs } \\
\text { F: LEFS, } \\
\text { AKPS, } \\
\text { SLHT }\end{array}$ & $\begin{array}{l}\text { I\& C: } \\
\text { I: } P \downarrow \& \text { \& } \uparrow: \text { all OM 12, 24, 52wks ( } p<0.05) \\
\text { C: } P \downarrow: \text { upstairs } 24 w k s ; \text { downstairs } 12, \\
\text { 24wks ( } p<0.05) \\
\quad F \uparrow: S L H T 12,24,52 \text { wks ( } p<0.05), \\
\text { others }(p>0.05) \\
\text { I vs C: } \\
P: \downarrow \& F: \uparrow(I>C) \text { : all OM 12, 24, 52wks } \\
(p<0.05)\end{array}$ \\
\hline $\begin{array}{l}\text { Ismail et } \\
\text { al. }{ }^{19}\end{array}$ & $\begin{array}{l}n=32 \\
23 F / 9 M \\
24 \pm 6(18-30)\end{array}$ & $\begin{array}{l}n=16 \text { Hip: } \\
\text { OKC AB \& } \\
\text { ER + Knee } \\
\text { Protocol } \\
\text { 3x/wk, 6wks }\end{array}$ & $\begin{array}{l}\mathrm{n}=16 \mathrm{Knee} \\
\text { Protocol: } \\
\text { squats, Kn } \\
\text { E, stretch } \\
\text { 3x/wk, 6wks }\end{array}$ & $\begin{array}{l}\text { P: VAS } \\
\text { F: AKPS } \\
\text { S: Dyn. } \\
\text { (AB, ER) }\end{array}$ & $\begin{array}{l}\text { I \& C: } \\
P: \downarrow(p=0.01, p=0.001 \text { resp.) } \\
F \& S: \uparrow \text { both }(p<0.05, p<0.05 \text { resp.) } \\
\text { I vs C: } \\
P: \downarrow \& F: \uparrow(I>C):(p=0.03) \&(p=0.04) \text { resp. } \\
S: \uparrow(I \text { cf } C):(p=0.25-0.43)\end{array}$ \\
\hline $\begin{array}{l}\text { Sahin et } \\
\text { al. }{ }^{20}\end{array}$ & $\begin{array}{l}n=55 \\
55 F \\
34.1 \pm 6.2(28-40) \\
\text { Sedentary }\end{array}$ & $\begin{array}{l}n=25 \text { Hip: } \\
\text { OKC AB \& } \\
\text { ER + Knee } \\
\text { Protocol } \\
\text { 12wks: } \\
\text { 5x/wk 6wks } \\
\text { supervised + } \\
\text { 6wks home }\end{array}$ & $\begin{array}{l}n=25 \text { Knee } \\
\text { Protocol: } \\
\text { squats, Kn } \\
\text { E, SLR, } \\
\text { stretch } \\
\text { 12wks: 6wks } \\
\text { supervised + } \\
\text { 6wks home }\end{array}$ & $\begin{array}{l}\text { P: VAS } \\
\text { F: (s) AKPS } \\
\text { (o) THT, } \\
\text { SLST \& } \\
\text { SDT } \\
\text { S: Dyn. } \\
\text { (KE, HF, } \\
\text { AB, ER) }\end{array}$ & $\begin{array}{l}\text { I \& C: } \\
P: \downarrow 6,12 \text { wks (both } p<0.001) \\
F: \uparrow \text { all 6, 12wks }(p<0.03 \text { except THT) } \\
\text { S: } \uparrow \text { all } 6,12 \text { wks ( } p \text { values not provided }) \\
\text { I vs C: } \\
P \downarrow(I>C): 6,12 w k s \text { (both } p=0.017) \\
F: \uparrow(I>C) \text { AKPS: 6, 12wks (both } p=0.017) ; \\
\quad \text { SLST: 6wks ( } p<0.017) ; \text { SDT: } 6,12 w k s \\
(p<0.017) \\
S: \uparrow(I>C): \text { AB + ER 6wks, ER 12wks } \\
(p \leq 0.027), \text { others } p>0.05\end{array}$ \\
\hline $\begin{array}{l}\text { Razeghi } \\
\text { et al. }{ }^{21}\end{array}$ & $\begin{array}{l}n=33 \\
33 F \\
22.6 \pm 2.7(18-30) \\
\text { Students }\end{array}$ & $\begin{array}{l}\mathrm{n}=16 \text { Hip: } \\
\text { resistive hip } \\
\text { ('all') + Knee } \\
\text { Protocol }\end{array}$ & $\begin{array}{l}n=16 \text { Knee } \\
\text { Protocol: }\end{array}$ & $\begin{array}{l}\text { P: VAS } \\
\text { S: digital } \\
\text { myometer } \\
\text { (HF, HE, }\end{array}$ & $\begin{array}{l}\text { I \& C: } \\
P: \downarrow(p=0.001, p=0.005 \text { resp. }) \\
\text { S: not reported } \\
\text { I vs C: }\end{array}$ \\
\hline
\end{tabular}




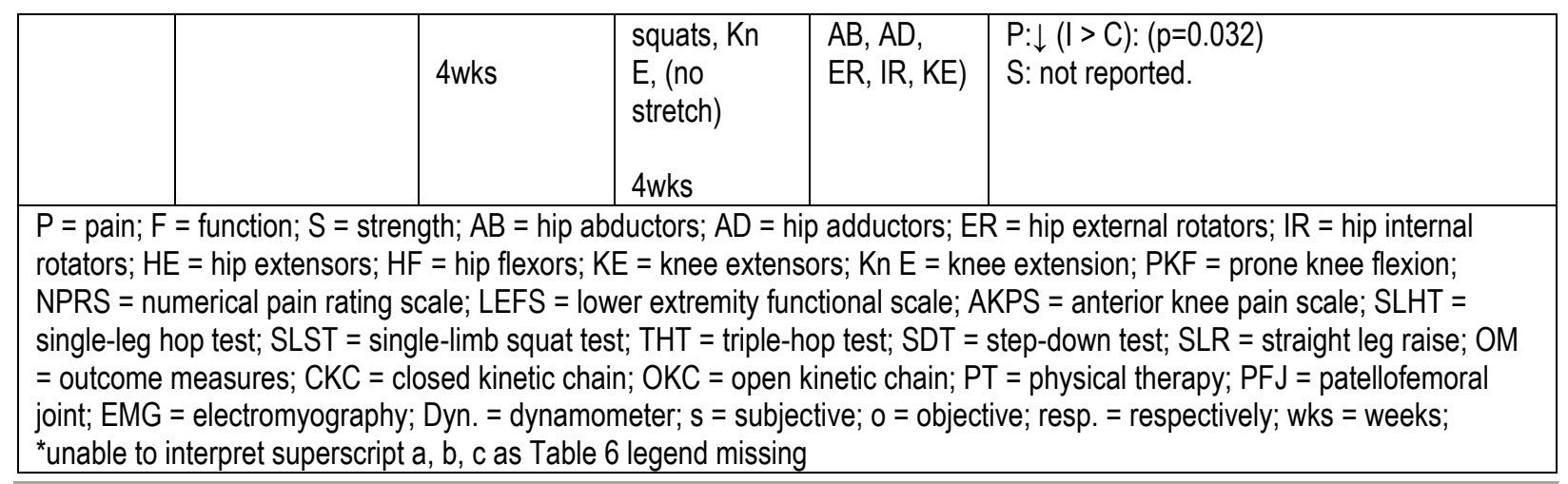

\section{Types of Intervention}

Across all studies the treatment protocol for the comparator consisted of quadriceps strengthening and stretching of surrounding knee musculature, whilst the intervention protocol included the addition of strengthening exercises targeting the hip muscles. Four studies clearly stated the intervention to include hip abductors and external rotators; $17-20$ with hip extensors included in one of these studies. ${ }^{18}$ The intervention periods across the studies for both intervention and comparator groups consisted of 4, 6 or, 12 week treatment programs, with training frequency ranging from three to five sessions per week. Sahin et al provided participants with supervised treatment sessions, however, no consistent significant differences in any of the outcomes were found between that study and the four remaining studies, which did not provide or report supervised treatment. $20,16,17,19,21$

\section{Outcomes}

Pain

Pain was rated in all studies, three using the VAS and two using the numerical pain rating scale (NPRS). All five studies demonstrated improvements, with decreased pain scores in those undertaking both the knee exercises only (control) and the combined hip and knee exercises (intervention), at all time points assessed (4, 6, \& 12 weeks and 6 \& 12 months). ${ }^{17-21}$ This indicates that knee-based treatments alone have positive effects on pain reduction. However, between group analyses showed that participants in the intervention groups had significantly more pain reduction post intervention and/or during all follow-ups, compared to the knee only exercise groups. Two studies that included a follow-up assessment found that pain continued to decrease during this time, suggesting the potential long-term benefits of strengthening both hip and knee muscles for pain reduction. 18,20

\section{Function}

Function was evaluated by four studies, all using the anterior knee pain scale (AKPS), which is also referred to as the Kujula questionnaire. This questionnaire considers objective knee findings and functional capabilities in conjunction with pain. ${ }^{17-20}$ All intervention groups employing both hip and knee exercises displayed significant improvement in function, whereas findings from the control groups were more inconsistent. Between group analyses agreed that those in the intervention group performing both hip and knee exercises had greater function at all follow-up $(4,6, \& 12$ weeks and 6 \& 12 months) than the comparator. Other outcome measures considered across studies included the LEFS, step down test, triple hop test, and single leg squat test. All studies found that both groups, irrespective of undertaking knee exercises alone or with hip exercises, had improved function at the end of their designated program. ${ }^{17-20}$

\section{Strength}

Muscle strength (varying combinations of hip abductors, hip external and internal rotators, hip flexors and extensors, and knee extensors) was assessed by three studies. ${ }^{19-21}$ Two of these studies used a dynamometer. ${ }^{19,20}$ One study used a myometer. ${ }^{21}$ One study reported increased strength in both intervention and comparator groups in the assessed muscles at each time point measured. ${ }^{19}$ However, interpretation of results of the remaining two studies assessing strength was unclear. ${ }^{20,21}$ Between group findings were inconsistent between the studies. Sahin et al. found that at 6 and 12 weeks, those undertaking both hip and knee exercises had greater strength (abductors and external rotators at six weeks, external rotators only at 12 weeks) than those performing knee exercises alone. ${ }^{20}$ Contrastingly, Ismail et al. found no significant difference in strength at six weeks between those performing both hip and knee exercises and those who performed knee exercises only. ${ }^{19}$ These results may be influenced by differences in treatment frequency and duration between the two studies. Sahin et al. held five sessions per week over six weeks (a total of 30 sessions) with an additional six-week home exercise program, whilst Ismail et al. only conducted three sessions per week over six weeks (a total of 18 sessions) without a home exercise program. ${ }^{19,20}$ 
Table 4: Summary of Results

\begin{tabular}{|l|c|c|c|}
\hline \multirow{2}{*}{ Study } & \multicolumn{3}{|c|}{ Outcomes } \\
\cline { 2 - 4 } & Pain & Function & Strength \\
\hline Fukuda et al. (2010) & $\downarrow^{*}$ & $\uparrow^{*}$ & N/A \\
\hline Fukuda et al. (2012) & $\downarrow^{*}$ & $\uparrow^{*}$ & $\leftrightarrow$ \\
\hline Ismail, Gamaleldein and Hassa $(2013)^{19}$ & $\downarrow^{*}$ & $\uparrow^{*}$ & $\uparrow$ \\
\hline Sahin et al. $(2016)^{20}$ & $\downarrow$ & $\uparrow$ & N/R \\
\hline Razeghi et al. $(2010)^{21}$ & $\downarrow^{*}$ & $\mathrm{~N} / \mathrm{A}$ & \\
\hline
\end{tabular}

Key:

$\mathrm{N} / \mathrm{A}=$ Not applicable (for this outcome measure in this study)

$\leftrightarrow=$ No difference (between intervention and comparator/ control)
$\mathrm{N} / \mathrm{R}=$ not reported

$\downarrow=$ Reduction with intervention (cf comparator/control)

$\uparrow=$ Increase with intervention (cf comparator/control)

$*=$ Results are statistically significant $(P<0.05)$

\section{NHMRC Body of Evidence Framework}

Table 5 synthesises the results of the included studies using the NHMRC FORM framework. ${ }^{15}$ The included studies, despite being classified as high-level evidence forms, could only be considered as moderate quality due to methodological concerns involving lack of blinding and true randomisation. Furthermore, the evidence base is somewhat mixed due to the focus being on different outcomes, using a range of outcome measures, as well as differing intervention programs. Therefore, despite results being largely positive for the efficacy of the addition of hip strengthening exercises to regular physiotherapy treatment, care should be taken when considering clinical application.

Table 5: NHMRC Body of Evidence Framework

\begin{tabular}{|c|c|c|}
\hline Component & Grade & Comments \\
\hline Evidence base & $\begin{array}{l}\text { C Satisfactory } \\
\text { One or two level III studies with a low } \\
\text { risk of bias }\end{array}$ & $\begin{array}{l}\text { Quantity: total of five studies } \\
\text { Level III: six studies } \\
\text { Quality: Moderate }\end{array}$ \\
\hline Consistency & $\begin{array}{l}\text { B Good } \\
\text { Most studies consistent and } \\
\text { inconsistency may be explained }\end{array}$ & $\begin{array}{l}\text { Consistent study design } \\
\text { Some variety in gender/s of population studied } \\
\text { Some variety in intensity, frequency and } \\
\text { duration of intervention } \\
\text { Some variety in outcome measures }\end{array}$ \\
\hline Clinical Impact & B Substantial & $\begin{array}{l}\text { Duration of therapy required to achieve effects } \\
\text { across all studies is clinically feasible } \\
\text { All intervention protocols were well described } \\
\text { All outcome measures reported on were of } \\
\text { substantial clinical significance } \\
\text { Findings for pain were consistent across all } \\
\text { studies } \\
\text { No adverse effects were reported } \\
\text { No long-term regression was reported by the } \\
\text { two studies that included follow up }\end{array}$ \\
\hline Generalisability & $\begin{array}{l}\text { C Satisfactory } \\
\text { Population/s studied in body of evidence } \\
\text { differ to target population for guideline } \\
\text { but it is clinically sensible to apply this } \\
\text { evidence to target population }\end{array}$ & $\begin{array}{l}\text { Population is consistent with the target } \\
\text { population in terms of age however not gender } \\
\text { Three of the five studies specifically } \\
\text { investigated sedentary females } \\
\text { Three studies conducted power calculations } \\
\text { where power was achieved } \\
\text { Studies conducted in four different countries, all } \\
\text { with different cultural and religious beliefs }\end{array}$ \\
\hline
\end{tabular}

(C) The Internet Journal of Allied Health Sciences and Practice, 2018 


\begin{tabular}{|l|l|l|}
\hline & & $\begin{array}{l}\text { No additional or specialised treatment or } \\
\text { equipment required for implementation } \\
\text { No studies conducted in Australia, however it } \\
\text { can be assumed that, based on mode and } \\
\text { nature of treatment, these treatment protocols } \\
\text { would be well adopted in Australian healthcare } \\
\text { Attitudes, beliefs (religious or otherwise), may } \\
\text { be contrasting and have an effect on } \\
\text { compliance and results }\end{array}$ \\
& $\begin{array}{l}\text { B Good } \\
\text { Applicable to Australian healthcare } \\
\text { context with few caveats }\end{array}$ & $\begin{array}{l}\text { The studies were of moderate quality } \\
\text { Homogenous findings across studies for at } \\
\text { least one of the three outcome measures } \\
\text { The current evidence is mixed with some } \\
\text { discrepancies in outcome measures, baseline } \\
\text { characteristics and intervention programs } \\
\text { Results of the review are most relevant to a } \\
\text { sedentary female population }\end{array}$ \\
\hline \multirow{G}{*}{ Grade of Recommendation } & $\begin{array}{l}\text { B Body of evidence can be trusted to } \\
\text { guide practice in most situations }\end{array}$ & \\
& &
\end{tabular}

\section{DISCUSSION}

The five studies included in the systematic review investigated the effectiveness of the addition of hip strengthening exercises to standard physiotherapy knee treatment on pain, strength, and function when compared to standard physiotherapy care alone in adults with PFPS.17-21 All five studies demonstrated significant improvements in pain scores in intervention compared to comparator groups, and the four studies that assessed function also reported significant comparative functional improvements. Of the three studies that measured strength, only Sahin et al. reported a significant increase in the hip strength for the abductors and external rotators in the intervention compared to the comparator group. ${ }^{20}$ No adverse effects of treatment were reported in any of the five studies. ${ }^{17-21}$

The results of this review are most applicable to young sedentary females. Although Ismail et al. ${ }^{19}$ included male participants in their study, across all studies the overall sample sizes were small, the power calculations limited, and males were underrepresented, making up only 9 out of a total of 244 (3.7\%) participants. The four other studies only included female participants classified as either 'sedentary' or 'not involved in professional sports activity.'17,18,20,21 Sahin et al. had a slightly older group of participants with mean age 34.1 years compared to all other studies with mean ages ranging from 22.6 to 25 years. ${ }^{20}$ Thus, the transferability of the results of the review is most appropriate for the young sedentary female population.

\section{Exercise type, Prescription \& Method of Delivery}

The results of this review indicate that additional open or closed-kinetic chain strengthening exercises targeting hip abductors, hip external rotators, and hip extensors can be effective in improving pain and function. Although there was variation in the frequency of interventions across studies and session durations were largely unreported, it may be useful for clinicians to know that there is moderate level evidence to suggest that significant and long-lasting improvements in both outcomes can be achieved with as little as 12 therapist-supervised sessions over four weeks. One of the great benefits for clinicians incorporating this management strategy is that it requires no additional training or equipment and can be undertaken at minimal cost. However, patients considering this form of management need to be motivated and willing to invest the time and costs associated with approximately 12, 30-minute visits over four weeks. At this stage, there is insufficient evidence to determine the effectiveness of a group-based exercise class or a similar home-based exercise program. Based on a study by Sahin et al. which included five sessions per week for six weeks with an additional six-week home exercise program, there is a suggestion that gains in strength may also be achieved with a more frequent and intense program. ${ }^{20}$

\section{Comparison with Previous Studies}

The recent systematic review by Santos et al. investigating a similar research question reported comparable findings. ${ }^{5}$ In addition to updating the search from September 2014 to September 2017, the current review searched a broader range of databases, yielding one additional study by Sahin et al. ${ }^{20}$ Furthermore, a more rigorous eligibility criteria was applied which resulted in the exclusion of three studies included in the Santos et al. review.9-11 In Dolak et al., the patients with PFPS undertook either a hip strengthening program or a knee strengthening program; then, both groups performed similar functional weight bearing exercises. ${ }^{9}$ In Khayambashi et al. study, the intervention group undertook hip abductor and external rotator strengthening and the control group was placed on an Omega 3 diet with no exercise..$^{10}$ In neither study was it considered that the effects of hip strengthening compared

(C) The Internet Journal of Allied Health Sciences and Practice, 2018 
to standard PFPS management could be discerned. ${ }^{9,10}$ In Nakagawa et al. study, the intervention group participated in a program consisting of both transverse abdominus exercises and hip strengthening exercises, which does not separate the isolated effect of hip strengthening exercises from standard physiotherapy care for PFPS. ${ }^{11}$ It is possible that the inclusion of these three studies may have inflated the results of the review by Santos et al. ${ }^{5}$ While there was agreement across the findings between the current review and that by Santos et al., the more focused research question and stricter exclusion criteria of the current review provides greater confidence in the results and application of these to clinical practice. ${ }^{5}$

\section{Limitations}

The systematic review has several limitations related to review processes, study outcomes, and methodology. A comprehensive search strategy including searching additional studies from related systematic reviews gleaned five studies that met the inclusion criteria. Another study by Soleimani et al. with an English abstract appeared to be current and relevant; however full text was accessible in Persian only, and was therefore excluded from the review. ${ }^{16}$

Common methodological concerns included lack of blinding to treatment, which is difficult in an ongoing physiotherapy program. Included studies were also mostly low-level research designs (NHMRC Level III-1 Intervention). They were unable to be classified as Level II randomised controlled trials due to the use of an envelope-based pseudo-randomisation process as opposed to a computer generated randomisation. ${ }^{15}$ Furthermore, one study was limited in participant continuity and between-group participant homogeneity, as well as in considering all clinically important outcomes. ${ }^{21}$ For the three main outcomes, pain, function, and strength, different outcome measures were used, resulting in an inability to undertake a meta-analysis, thus preventing combining the data from a number of studies to identify the overall effect. Power calculations were utilised and achieved in three of the five included studies. ${ }^{17,18,21}$ In a fourth study, the sample size was based on a previous study. ${ }^{19}$ All studies utilised minimal clinically important difference (MCID) to detect clinical significance, however not for all outcome measures. Although two studies used MDIC to determine improvement in both pain and function (and strength was not assessed) ${ }^{17,18}$, the remaining three studies only utilised it to determine clinical significance of pain, not function or strength. ${ }^{19-21}$ It was not specified in any of the three studies assessing dynamometer or myometer strength whether the findings were normalized to measures of body size (e.g. body mass or height, to remove body-size dependence). ${ }^{19,20,21}$ Although findings were persuasive, some caution is therefore required in drawing indisputable clinical conclusions.

With respect to participant status, the majority of studies focused on females alone, with three recruiting specifically sedentary females. While Ismail et al. considered both genders, the majority of participants were female. ${ }^{19}$ As a result, evidence within this systematic review is limited regarding efficacy of application to a male population. Finally, research team members recognise the possibility of reporting bias, as all included studies had positive findings for at least one outcome.

\section{CONCLUSIONS}

\section{Implications for Clinical Practice}

Overall, it can be concluded that within the limitation of poorer quality of some of the included studies, the addition of hip strengthening exercises to standard physiotherapy treatment results in greater improvements in both pain and function for adults with PFPS, compared with standard physiotherapy care alone. There is less confidence in the findings for changes in strength. More specifically, significant improvements in both pain and function can be gained through a program including knee and hip exercises undertaken for as little as three times per week over four weeks, with potential for additional benefit of improved strength to occur with a more regular program of five times per week over six weeks. It should be noted, however, that the majority of studies in this review focused on sedentary females, so results are most relevant to this population.

\section{Implications for Future Research}

With reference to individual studies, recommendations for future research include allocation of both male and female participants with recruitment of a sufficiently large sample to allow for subgroup analysis of gender differences. The use of a true control in addition to intervention and comparator groups is also recommended. Further considerations include addressing all clinically important outcomes (pain, strength and function), utilising minimal clinically important difference (MCID) for all outcome measures used to consider clinical significance, providing normalised strength values for better interpretation of the findings, refining the randomisation process, and consistent use of power calculations. It may also be beneficial to further explore the effectiveness of a home exercise program following supervised and group classes for the first four weeks, which may offer future direction for clinicians. In terms of methodology, accepting only a particular measure for inclusion for each main outcome would increase consistency of results and improve the ability to form clearer comparisons between studies.

(C) The Internet Journal of Allied Health Sciences and Practice, 2018 


\section{REFERENCES}

1. Crossley KM, Van Middelkoop M, Callaghan MJ, Collins NJ, Rathleff MS, Barton CJ. Patellofemoral pain consensus statement from the 4th International Patellofemoral Pain Research Retreat, Manchester. Part 2: recommended physical interventions (exercise, taping, bracing, foot orthoses and combined interventions). Br J Sport Med. 2016;50(14):844-52. [PMID: 27247098]

2. Boling M, Padua D, Marshall S. Gender differences in the incidence and prevalence of patellofemoral pain syndrome. Scand J Med Sci Sports. 2010;20(5):725-30. [PMID: 19765240]

3. Davis IS, Powers C. Patellofemoral pain syndrome: proximal, distal and local factors, an international retreat. J Orthop Sports Phys Ther. 2010;40(3):A1-16. [PMID: 20195028]

4. Fredericson M, Powers CM. Practical management of patellofemoral pain. Clin J Sport Med. 2002;12(1):36-8. [PMID: 11854587]

5. Santos T, Oliveira B, Ocarino J, Holt K, Fonseca S. Effectiveness of hip muscle strengthening in patellofemoral pain syndrome patients: a systematic review. Braz J Phys Ther. 2015;19(3):167-76. [PMID: 26039034]

6. Garcia FR, Azevedo FM, Alves N, Carvalho AC, Padovani CR, Negrao RF. Effects of electrical stimulation of vastus medialis obliquus muscle in patients with patellofemoral pain syndrome: an electromyographic analysis. Rev Bras Fisioter. 2010;14(6):477-82. [PMID: 21340241]

7. Barton CJ, Lack S, Hemmings S, Tufail S, Morrissey D. The 'Best practice guide to conservative management of patellofemoral pain': incorporating level 1 evidence with expert clinical reasoning. Br J Sports Med. 2015;49(14):92334. [PMID: 25716151]

8. Powers CM. The influence of altered lower-extremity kinematics on patellofemoral joint dysfunction: a theoretical perspective. J Orthop Sports Phys Ther. 2003;33(11):639-46. [PMID: 14669959]

9. Dolak KL, Silkman C, McKeon JM, Hosey RG, Lattermann C, Uhl TL. Hip strengthening prior to functional exercises reduces pain sooner than quadriceps strengthening in females with patellofemoral pain syndrome: a randomized clinical trial. J Orthop Sports Phys Ther. 2011;41(8):560-70. [PMID: 21654093]

10. Khayambashi K, Fallah A, Movahedi A, Bagwell J, Powers C. Posterolateral hip muscle strengthening versus quadriceps strengthening for patellofemoral pain: a comparative control trial. Arch Phys Med Rehabil. 2014;95(5):9007. [PMID: 24440362]

11. Nakagawa TH, Muniz TB, Baldon DM, Dias MC, De RB, Serrão FV. The effect of additional strengthening of hip abductor and lateral rotator muscles in patellofemoral pain syndrome: a randomized controlled pilot study. Clin Rehabil. 2008;22(12):1051-60. [PMID: 19052244]

12. Sallis R, Franklin B, Joy L, Ross R, Sabgir D, Stone J. Strategies for promoting physical activity in clinical practice. Prog Cardiovasc Dis. 2015;57(4):375-86. [PMID: 25459975]

13. Shamseer L, Moher D, Clarke M, Ghersi D, Liberati A, et al. Preferred reporting items for systematic review and metaanalysis protocols (PRISMA-P) 2015: elaboration and explanation. BMJ. 2015;349:g7647. [PMID: 25555855]

14. Critical Appraisal Skills Programme (CASP) Randomised Controlled Trial Checklist. CASP UK 2017. Available at: <http://docs.wixstatic.com/ugd/dded87_4239299b39f647ca9961f30510f52920.pdf>. Accessed September 9, 2017.

15. National Health and Medical Research Council. NHMRC additional levels of evidence and grades for recommendations for developers of guidelines. Australian Government. 2009. Available at: $<$ https://www.nhmrc.gov.aul_files_nhmrc/file/guidelines/developers/nhmrc_levels_grades_evidence_120423.pdf>. Accessed October 18, 2017.

16. Soleimani F, Derisfard F, Negahban H, Esfandiarpour F. Effectiveness of knee exercises versus combined knee and hip exercises in treatment of patellofemoral pain: a randomized clinical trial [Persian]. Koomesh. 2017;19(3):554-64.

17. Fukuda TY, Rossetto FM, Magalhães E, Bryk FF, Lucareli RG, De CN. Short-term effects of hip abductors and lateral rotators strengthening in females with patellofemoral pain syndrome: a randomized controlled clinical trial. J Orthop Sports Phys Ther. 2010;40(11):736-42. [PMID: 21041965]

18. Fukuda TY, Melo WP, Zaffalon BM, Rossetto FM, Magalhães E, et al. Hip posterolateral musculature strengthening in sedentary women with patellofemoral pain syndrome: a randomized controlled clinical trial with 1-year follow-up. J Orthop Sports Phys Ther. 2012;42(10):823-30. [PMID: 22951491]

19. Ismail MM, Gamaleldein KA, Hassa KA. Closed Kinetic Chain exercises with or without additional hip strengthening exercises in management of Patellofemoral pain syndrome: a randomized controlled trial. Eur J Phys Rehabil Med. 2013;49(5):687-98. [PMID: 23820880]

20. Sahin M, Ayhan F, Borman P, Atasoy H. The effect of hip and knee exercises on pain, function, and strength in patients with patellofemoral pain syndrome: a randomized controlled trial. Turk J Med Sci. 2016;46(2):265-77. [PMID: 27511483]

21. Razeghi M, Etemadi $\mathrm{Y}$, Taghizadeh S, Ghaem H. Could hip and knee muscle strengthening alter the pain intensity in patellofemoral pain syndrome? IRCMJ. 2010;12(2):104-10.

(c) The Internet Journal of Allied Health Sciences and Practice, 2018 
Appendix 1: Search Strategy

\begin{tabular}{|c|c|c|c|c|c|c|}
\hline \multicolumn{7}{|c|}{ Primary Databases } \\
\hline \multirow[t]{2}{*}{ E-Databases } & \multicolumn{6}{|c|}{ Search Terms } \\
\hline & $\mathbf{P}$ & I & C & 0 & Limits & Specification \\
\hline $\begin{array}{l}\text { MEDLINE } \\
\text { Embase }\end{array}$ & $\begin{array}{l}\text { Patellofemoral } \\
\text { Pain Symdrome/ } \\
\text { ("PFPS" OR } \\
\text { "PFJS" OR } \\
\text { "patellofemoral } \\
\text { pain syndrome" } \\
\text { OR } \\
\text { "patellofemoral } \\
\text { joint syndrome" } \\
\text { OR "runner* } \\
\text { knee") }\end{array}$ & $\begin{array}{l}\text { Exercise Therapy/ } \\
\text { Stretching/ Strengthening/ } \\
\text { ("hip strength*" exercise" } \\
\text { OR "hip exercis* (prev. } \\
\text { exercises*) OR "hip } \\
\text { strengthen*" (prev. } \\
\text { strengthening") } \\
\text { OR ("hip abduct*" OR "hip } \\
\text { extens*" OR "hip external } \\
\text { rotat*" OR "hip lateral rotat*" } \\
\text { OR "gluteus" OR "TFL" OR } \\
\text { "tensor fasciae latae" OR } \\
\text { "tensor fascia lata") adj3 } \\
\text { (strength* OR exercis*)) }\end{array}$ & $\begin{array}{l}\text { None } \\
\text { used in } \\
\text { search } \\
\text { strategy }\end{array}$ & $\begin{array}{l}\text { Treatment } \\
\text { Outcome/ } \\
\text { (pain OR } \\
\text { function* OR } \\
\text { "hip } \\
\text { strength*) }\end{array}$ & $\begin{array}{l}\text { English } \\
\text { Language } \\
\text { Humans } \\
\text { Adult (19-44 } \\
\text { years) }\end{array}$ & $\begin{array}{l}\text { MeSH headings } \\
\text { (Patellofemoral } \\
\text { Pain Syndrome) } \\
\text { and Keywords } \\
\text { Truncations } \\
\text { Phrase searching } \\
\text { (in intervention, } \\
\text { used "adj3" = } \\
\text { within } 3 \text { words) }\end{array}$ \\
\hline $\begin{array}{l}\text { SportDiscus } \\
\text { CINAHL }\end{array}$ & $\begin{array}{l}\text { "PFPS" OR } \\
\text { "PFJS" OR } \\
\text { "patellofemoral } \\
\text { pain syndrome" } \\
\text { OR } \\
\text { "patellofemoral } \\
\text { joint syndrome" } \\
\text { OR "runner" } \\
\text { knee" }\end{array}$ & $\begin{array}{l}\text { "hip strength" exercise*" } \\
\text { OR "hip exercis* (prev. } \\
\text { exercises*) OR "hip } \\
\text { strengthen*" (prev. } \\
\text { strengthening") } \\
\text { OR ("hip abduct" OR "hip } \\
\text { extens"” OR "hip external } \\
\text { rotat*" OR "hip lateral rotat" }^{*} \text { OR "gluteus" OR "TFL" OR } \\
\text { "tensor fasciae latae" OR } \\
\text { "tensor fascia lata") N3 } \\
\text { (strength* OR exercis*) }\end{array}$ & & $\begin{array}{l}\text { pain or } \\
\text { function* or } \\
\text { "hip } \\
\text { strength" }\end{array}$ & $\begin{array}{l}\text { English } \\
\text { language }\end{array}$ & $\begin{array}{l}\text { Subject headings } \\
\text { (PLICA } \\
\text { syndrome) } \\
\text { Truncations } \\
\text { Phrase searching } \\
\text { (in intervention, } \\
\text { used "N3" = within } \\
3 \text { words of ) }\end{array}$ \\
\hline \multicolumn{7}{|c|}{ Secondary Databases } \\
\hline Cochrane & $\begin{array}{l}\text { PFPS OR PFJS } \\
\text { OR } \\
\text { patellofemoral } \\
\text { pain syndrome } \\
\text { OR } \\
\text { patellofemoral } \\
\text { joint syndrome }\end{array}$ & $\begin{array}{l}\text { hip strength* exercise* OR } \\
\text { hip exercise* OR hip } \\
\text { strengthening }\end{array}$ & $\begin{array}{l}\text { None } \\
\text { used in } \\
\text { search } \\
\text { strategy }\end{array}$ & $\begin{array}{l}\text { pain or } \\
\text { function* OR } \\
\text { hip strength }\end{array}$ & Nil & $\begin{array}{l}\text { Subject headings } \\
\text { and Keywords } \\
\text { Truncation }\end{array}$ \\
\hline PEDro & $\begin{array}{l}\text { Patellofemoral } \\
\text { pain syndrome } \\
\text { OR } \\
\text { patellofemoral } \\
\text { joint syndrome }\end{array}$ & $\begin{array}{l}\text { Strength training } \\
\text { Lower leg or knee } \\
\text { Musculoskeletal }\end{array}$ & & Strength & Clinical trial & $\begin{array}{l}\text { Subject headings } \\
\text { and Keyword }\end{array}$ \\
\hline
\end{tabular}


Appendix 2: Exercise Prescription

\begin{tabular}{|c|c|c|}
\hline Study & Intervention (I) & Comparator (C) \\
\hline $\begin{array}{r}\text { Fukuda et al. } \\
2010^{16}\end{array}$ & $\begin{array}{l}\text { [12 sessions, 3x/wk, 4wks] } \\
\text { HIP } \\
\text { Abd: stand against elastic resistance 10RM 3×10 } \\
\text { reps; sidelying with weight } 70 \% 1 \mathrm{RM} 3 \times 10 \text { reps; side } \\
\text { step against elastic resistance } 3 \times 1 \mathrm{~min} \\
\text { ER: sit against elastic resistance 10RM 3x10 reps. } \\
\text { (10RM adjusted weekly) } \\
+ \\
\text { KNEE (see comparator) }\end{array}$ & $\begin{array}{l}\text { [12 sessions, 3x/wk, 4wks] } \\
\text { KNEE } \\
\text { Stretching 3x30s (ITB, HS, Q, G) } \\
\text { lliopsoas NWB 70\% 1RM 3x10 reps } \\
\text { Sitting knee } E\left(90-45^{\circ}\right) 70 \% 1 \text { RM } 3 \times 10 \text { reps } \\
\text { Leg press }\left(0-45^{\circ}\right) 70 \% 1 \text { RM } 3 \times 10 \text { reps } \\
\text { Mini-squat }\left(0-45^{\circ}\right) 70 \% 1 \text { RM } 3 \times 10 \text { reps }\end{array}$ \\
\hline $\begin{array}{l}\text { Fukuda et } \\
\text { al. } 2012^{17}\end{array}$ & 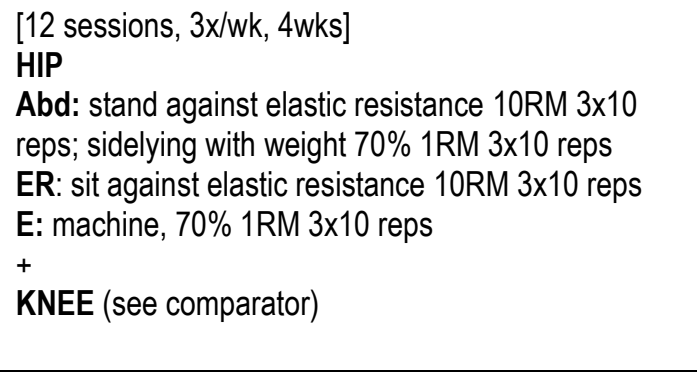 & 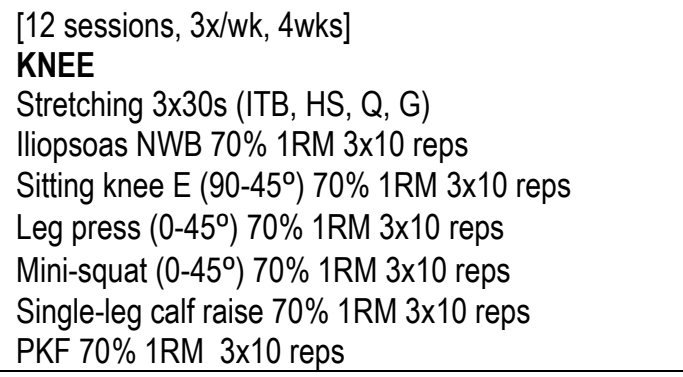 \\
\hline $\begin{array}{l}\text { Ismail, } \\
\text { Gamaleldein } \\
\text { and Hassa } \\
2013^{18}\end{array}$ & $\begin{array}{l}\text { [18 session, } 3 \times / \text { wk, } 6 \text { wks] } \\
\text { HIP } \\
\text { Abd: sidelying with ankle cuff weight, } 60 \% 10 \text { RM } \\
2 \times 10 \text { reps, 6s hold } \\
\text { ER: sit with ankle cuff weight } 60 \% 10 \mathrm{RM}, 2 \times 10 \text { reps, } \\
6 \text { s hold (10 RM adjusted weekly) } \\
+ \\
\text { KNEE (see comparator) }\end{array}$ & $\begin{array}{l}\text { [18 session, } 3 \times / w k, 6 \text { wks] } \\
\text { KNEE } \\
\text { Mini-squats } 0-40^{\circ} \text { with ball squeeze } 6 \text { s hold } \\
\text { f/w and lateral step up (8inch height) } 6 \text { s hold } \\
\text { Standing knee E } 30^{\circ} 6 \text { s hold against elastic } \\
\text { resistance } \\
\text { Stretching } 3 \times 30 \text { s (ITB, HS, Q, G) }\end{array}$ \\
\hline $\begin{array}{l}\text { Sahin et al. } \\
2016^{19}\end{array}$ & $\begin{array}{l}\text { [30 sessions, } 5 \times / w k, 6 \text { wks, } 30 \text { min] } \\
\text { All } 100 \% \text { of } 10 R M, 1 \times 10 \text { reps } \\
\text { HIP } \\
\text { Abd: stand against elastic resistance }\left(0 \text { to } 30-35^{\circ}\right) \\
3.5 \text { s hold, } 5 \text { reps } x 2 \text { daily ( } 5 \text { reps added weekly) } \\
\text { ER: sitting elastic resistance }\left(0 \text { to } 30^{\circ}\right) 3.5 \text { s hold, } 5 \\
\text { reps } x 2 \text { daily (5reps added weekly) } \\
+ \\
\text { KNEE (see comparator) } \\
+ \\
\text { 6wks at home exercise program }\end{array}$ & $\begin{array}{l}\text { [30 sessions, } 5 \times / \text { wk, } 6 \text { wks, } 30 \text { min] } \\
\text { KNEE } \\
\text { Stretching } 3 \times 10 \text { s } 2 \times \text { daily (ITB, HS, Q, G) } \\
\text { Supine isometric } Q \text { with towel } 10 \text { s hold } 20 \text { reps } \times 2 \\
\text { daily (5reps added weekly) } \\
\text { SLR } 3.5 \text { s hold } 10 \text { reps } \times 2 \text { daily } \\
\text { Mini-squats } 30-45^{\circ} 10 \text { s hold, } 10 \text { reps } \times 2 \text { daily } \\
\text { Sitting resisted knee } E \text { against resistance band } 3.5 \text { s } \\
\text { hold, } 5 \text { reps } \times 2 \text { daily (5reps added weekly) } \\
+ \\
\text { 6wks at home exercise program }\end{array}$ \\
\hline $\begin{array}{l}\text { Razeghi et } \\
\text { al. } 2010^{20}\end{array}$ & $\begin{array}{l}\text { [4wks (no further detail)] } \\
\text { HIP: progressive resisted hip exercises for 'all' hip } \\
\text { muscles (no further detail on exercise or prescription) } \\
+ \\
\text { KNEE: (see comparator) }\end{array}$ & $\begin{array}{l}\text { [4wks (no further detail)] } \\
\text { KNEE: mini-squats, resisted knee } E \text { terminal and } 90^{\circ} \\
\text { to } 50^{\circ} \text { (no further detail on prescription) }\end{array}$ \\
\hline
\end{tabular}

(c) The Internet Journal of Allied Health Sciences and Practice, 2018 